\title{
O CONTEXTO DAS TECNOLOGIAS ASSISTIVAS NA EDUCAÇÃO ESPECIAL E INCLUSIVA E O PANORAMA DA CAPACITAÇÃO DE DOCENTES
}

\section{THE CONTEXT OF ASSISTIVE TECHNOLOGIES IN SPECIALAND INCLUSIVE EDUCATION AND THE BACKGROUND OF TEACHER CAPACITATION}

\author{
Felipe Adriano Wojcikiewicz ${ }^{1}$ \\ Elton Moura Nickel², D. Sc. \\ (1) Universidade do Estado de Santa Catarina - UDESC \\ e-mail: lipewcz@gmail.com \\ (2) Universidade do Estado de Santa Catarina - UDESC \\ e-mail: eltonnickel@gmail.com
}

Tecnologias assistivas, Educação, Capacitação de docentes

\begin{abstract}
Este artigo traz uma revisão bibliográfica acerca do contexto do uso de tecnologias assistivas na educação especial e inclusiva, bem como um panorama sobre a capacitação de professores para atuação nessa área. A pesquisa aborda de forma hermenêutica um debate atual sobre o tema, de forma a interpretar e compreender suas rupturas, contradições e percepções sobre a interação humana com as tecnologias, com a produção de conhecimento e inclusão social. Essa investigação possibilita conhecer melhor o cenário de pesquisas sobre o tema, podendo se observar como são estabelecidos atualmente os processos pedagógicos através do uso dessas tecnologias.
\end{abstract}

\section{Assistive technologies, Education, Teacher training}

This paper presents a literature review about the context of the use of assistive technologies in special and inclusive education, as well as a panorama on the teacher's capacitation to work in this area. The research approaches hermeneutically a current debate on this theme, in order to interpret and understand its ruptures, contradictions and perceptions about human interaction with technologies, with the knowledge production and social inclusion. This research allows us to better understand the research scenario on the subject, and it is possible to observe how pedagogical processes are currently established through the use of these technologies.

\section{Considerações Iniciais}

Uma grande parcela da população é composta por pessoas com algum tipo de deficiência. E a maioria ainda vive num contexto de segregação, onde barreiras humanas, sociais e arquitetônicas resultam em restrições ao exercício da cidadania e de uma vida digna e participativa. Conforme CAMBIAGHI e YOUSSEF (2007), a inclusão diz respeito à mudança de olhar sobre o mundo, sobre as relações, sobre os direitos. Diz respeito à
Realização:
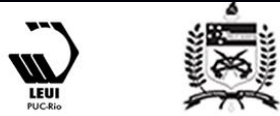


\section{$16^{\circ}$ \\ ERGODESIGN USIHC CINAHPA}

percepção interna de cada indivíduo. A sociedade (e o indivíduo com deficiência também) se modifica para que todos possam viver em igualdade de oportunidades.

O Decreto Federal 5.296/04, em seu art. 61, define Ajudas Técnicas como "produtos, instrumentos e equipamentos ou tecnologias adaptadas ou especialmente projetadas para melhorar a funcionalidade da pessoa portadora de deficiência ou com mobilidade reduzida, favorecendo autonomia pessoal total ou assistida" (BRASIL, 2004, p.12).

Para COOK e POLGAR (2008), Tecnologias Assistivas (ou simplesmente T.A.) são as tecnologias utilizadas para melhorar a autonomia e a qualidade de vida das pessoas com deficiência. O Human Activity Assistive Technology Model, ou Modelo HAAT (figura 1), é o método mais usado para descrever a T.A., definindo para o terapeuta/ergonomista quais fatores considerar ao avaliar qual equipamento assistivo é mais apropriado para uma pessoa com um determinado tipo de deficiência.

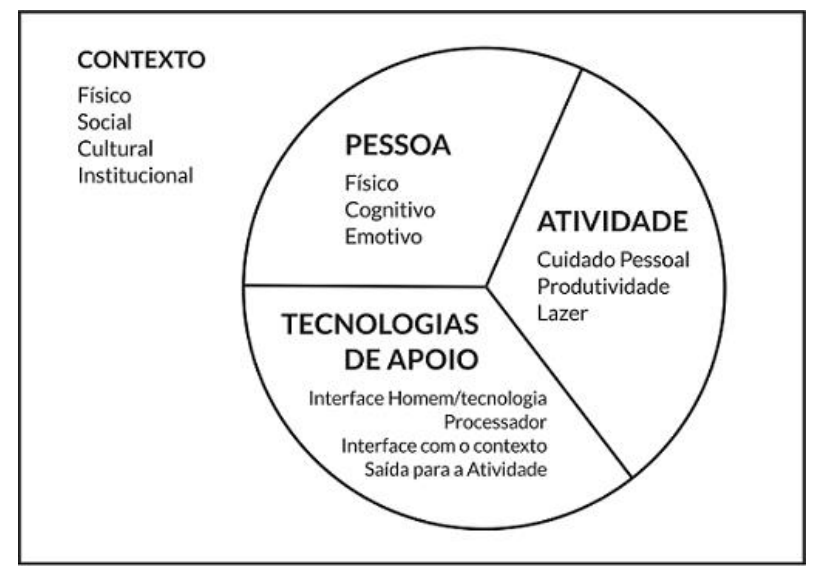

Figura 1: Modelo HAAT, contexto da pessoa com deficiência.

Fonte: Cook \& Polgar 2008

Um dos fatores preponderantes para se promover a inclusão das pessoas com deficiência é a educação. Segundo KLEINA (2012), educadores devem sempre acreditar na premissa que todos os alunos podem aprender algo novo, independentemente do seu nível de dificuldade. Quando o aluno não $16^{\circ}$ Ergodesign - Congresso Internacional de Ergonomia e Usabilidade de Interfaces Humano Tecnológica: Produto, Informações Ambientes Construídos e Transporte

$16^{\circ}$ USIHC - Congresso Internacional de Ergonomia e Usabilidade de Interfaces Humano Computador

CINAHPA | 2017 - Congresso Internacional de Ambientes Hipermídia para Aprendizagem.

consegue evoluir com um determinado modo de trabalho, então deve se pensar no que modificar na prática docente para favorecer sua aprendizagem; quais alternativas, recursos, equipamentos ou dispositivos existentes para ajudá-lo nesse processo.

Assim, é objetivo deste artigo desenvolver uma revisão bibliográfica acerca do uso de T.A.'s na educação especial, abordando seu contexto, sua importância no desenvolvimento de atividades pedagógicas e a promoção de qualidade de vida. É também objetivo deste artigo uma revisão bibliográfica sobre o panorama da capacitação de docentes para atuação na educação especial.

\section{Contexto do Uso de Tecnologias Assistivas na Educação Especial}

A educação especial assume o papel de organizar os meios necessários para desenvolver os potenciais das pessoas com necessidades especiais, seja em escolas especializadas ou não. Ou seja, assume o caráter de escola paralela, mas como um conjunto de medidas que a escola regular dispõe para o atendimento das necessidades especiais dos alunos (OLIVEIRA; GLAT, 2003).

As Diretrizes Operacionais do Atendimento Educacional Especializado (AEE), em seu Art.13, definem como uma das atribuições do professor "VII - ensinar e usar a T.A. de forma a ampliar habilidades funcionais dos alunos, promovendo autonomia e participação" (BRASIL, 2009, p. 17).

Recursos de T.A. são objetos de trabalho dos professores, porém a falta de conhecimento específico dos recursos inviabiliza o planejamento eficaz para promover momentos de aprendizagem significativa (HUMMEL, 2015). As T.A.'s não compreendem apenas as ditas "tecnologias de ponta", mas todos e quaisquer recursos, ferramentas e práticas educacionais ou materiais didáticos elaborados para possibilitar a participação autônoma e efetiva do estudante.

T.A. é uma área do conhecimento, de característica interdisciplinar, que engloba produtos, recursos,
Realização:

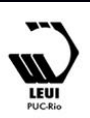




\section{$16^{\circ}$ \\ ERGODESIGN USIHC CINAHPA}

$16^{\circ}$ Ergodesign - Congresso Internacional de Ergonomia e Usabilidade de Interfaces Humano Tecnológica: Produto, Informações Ambientes Construídos e Transporte

$16^{\circ}$ USIHC - Congresso Internacional de Ergonomia e Usabilidade de Interfaces Humano Computador

CINAHPA | 2017 - Congresso Internacional de Ambientes Hipermídia para Aprendizagem. metodologias, estratégias, práticas e serviços que objetivam promover a funcionalidade, relacionada à atividade e participação, de pessoas com deficiência, incapacidades ou mobilidade reduzida, visando sua autonomia, independência, qualidade de vida e inclusão social (BRASIL, 2009, p. 3).

O entendimento de CONTE e BASEGIO (2015) sobre as T.A.'s como ferramentas para a educação inclusiva, aborda as diversas perspectivas em que se estabelecem as relações entre as tecnologias de interação e a produção do conhecimento. $\mathrm{O}$ intuito é sistematizar as vantagens dessas tecnologias no processo de ensino e de aprendizagem. Compreender que a educação deva transcender a capacidade estritamente operacional das tecnologias e abarcar todas as dimensões da formação humana. Ou seja, pode se identificar fortes indícios de que a integração das T.A.'s nos procedimentos escolares se legitima como mediação importante para assegurar às práticas educativas, processos de inclusão social, autonomia, intercâmbio e socialização de conhecimentos e especialmente de respeito às diferenças.

Para MANZINI e SANTOS (2002) a primeira etapa para a implementação do recurso de T.A. na escola é permitir ao profissional entender a situação que envolve o estudante: quais seus desejos, características físicas, psicomotoras e comunicativas, dinâmica do estudante no ambiente escolar, contexto social e também as necessidades dos professores para ampliar a participação do aluno no processo de ensino e aprendizagem. Para VALENTE (1991), muitas vezes a capacidade de aprendizagem do educando é limitada porque não lhe são oferecidas as ferramentas adequadas para seu próprio desenvolvimento. Por isso o ideal é que o próprio indivíduo possa explorar sua nova T.A. e participar das adequações necessárias, indicando formas de uso mais produtivas.

As T.A.'s não são dispositivos que permitem ao aluno com deficiência desempenhar suas tarefas da mesma forma como os demais alunos. Sua principal função é permitir ao aluno poder desempenhar as atividades do seu jeito, fornecendo-lhe autonomia em seu processo de aprendizagem.

Deve ainda ser repensada a produção expressiva das T.A.'s no cenário educacional, no sentido de potencializar o desenvolvimento da aprendizagem dos alunos, assim como um mecanismo para desacomodar preconceitos históricos de práticas pedagógicas ultrapassadas. Todavia, nota-se que a utilização das T.A.'s encontra-se atrelada, de sobremaneira, às restrições de ordem cultural, econômica e social do cotidiano escolar. E justamente através dessa lógica que se observa uma tensão que exige esforço para o conhecimento, criando uma sensação de indiferença ou negação de avanços e possibilidades.

Ao se falar em T.A.'s na área educacional, muitas alternativas de baixo custo podem ser produzidas artesanalmente, a fim de contemplar as necessidades do contexto escolar (engrossadores para lápis e canetas, pranchetas para livros, órteses moldáveis, adaptadores para tesouras), assim como conjuntos de objetos destinados às atividades básicas diárias (canecas, prato, talheres, escova dental). Para BERSCH e PELOSI (2006), desenvolver um dispositivo de T.A. na escola é buscar, com criatividade, uma estratégia para que o aluno realize suas tarefas "de outro jeito", valorizando seu jeito de fazer e de aumentar suas capacidades de ação e interação a partir de suas habilidades. Além disso, envolve o aluno ativamente tirando ele da condição de espectador, dando-lhe a oportunidade de experimentar e conhecer, construindo de forma individual e coletivamente novos conhecimentos.

De acordo com KLEINA (2012), desenvolver um recurso de T.A. para um aluno com deficiência também contribui para o aprimoramento do atendimento aos demais alunos. $\mathrm{O}$ desenvolvimento e o uso da T.A. traz aos educadores a necessidade de estudar, conhecer, observar avaliar e propor novas modificações, tanto em termos de materiais utilizados quanto em termos de prática docente, trazendo como consequências graduais melhorias no processo de ensino e aprendizagem. Segundo MERCADO
Realização:

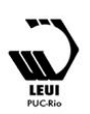




\section{$16^{\circ}$ \\ ERGODESIGN USIHC CINAHPA}

$16^{\circ}$ Ergodesign - Congresso Internacional de Ergonomia e Usabilidade de Interfaces Humano Tecnológica: Produto, Informações Ambientes Construídos e Transporte

$16^{\circ}$ USIHC - Congresso Internacional de Ergonomia e Usabilidade de Interfaces Humano Computador

CINAHPA | 2017 - Congresso Internacional de Ambientes Hipermídia para Aprendizagem.
(2002), o uso adequado das T.A.'s em processos de ensino e de aprendizagem favorece a representação mental do conhecimento. Para isso, o aluno usa de várias estratégias de pensamento e torna-se autônomo na construção do seu saber.

\section{Capacitação de Docentes}

Qualidade de vida e inclusão social não dizem respeito unicamente ao usuário da T.A., mas também ao correto uso dos dispositivos por parte da pessoa que auxilia o usuário, seja ela um educador, responsável pelo transporte ou mesmo uma pessoa do círculo familiar ou social desse usuário. Estar capacitado para auxiliar um indivíduo com deficiência no uso de dispositivos para desempenhar alguma tarefa implica diretamente em possibilitar que o próprio indivíduo faça o uso correto e pleno do dispositivo que lhe foi desenvolvido. É necessário saber posicionar e afixar o dispositivo corretamente, além de permitir ao indivíduo o desempenho das atividades a que se destina.

Conforme NICKEL (2012), na implementação das T.A.'s, é fundamental prover formação aos docentes. Por isso propõe-se um processo de apoio que trata da formação e capacitação continuada de docentes, cabendo aos responsáveis a organização das formações necessárias de modo que todos os profissionais recebam treinamento adequado, inclusive em caráter preparatório.

CONTE e BASEGIO (2015), salientam que as T.A.'s raramente são utilizadas nos planejamentos de aulas ou inseridas na formação de docentes. Nota-se que trabalhos de pesquisa sobre a formação de docentes em contextos inclusivos constituem uma temática quase que marginal.

Diversas ações, políticas públicas, educacionais e administrativas vem sendo implantadas e reformuladas ao longo da história, no intuito de promover a educação inclusiva em diversos contextos, como por exemplo, a Lei de Diretrizes e Bases da Educação nº 9.394 de 1996, que afirma em seu Artigo 59 que os sistemas de ensino devam assegurar aos alunos "currículos, métodos, técnicas, recursos e organização específicos, para atender às suas necessidades", assim como "professores com especialização adequada em nível médio ou superior, para atendimento especializado" (BRASIL, 1996).

Atualmente os cursos de formação de docentes já vêm sendo repensados e se adequando às novas legislações do sistema educacional: a Resolução $\mathrm{CNE} / \mathrm{CP} \mathrm{n}^{\circ} 1 / 2002$, institui Diretrizes Curriculares Nacionais para a Formação de Professores da Educação Básica, determinando que caiba às instituições de ensino superior "prever em sua organização curricular formação docente voltada para a atenção à adversidade" e que os projetos político-pedagógicos devem contemplar conteúdos curriculares com "conhecimento sobre as especificidades dos alunos com dificuldades educacionais especiais" (BRASIL. 2002). Porém, conforme HUMMEL (2015) os currículos ainda não contemplam conhecimentos suficientes para que os futuros docentes sejam capazes de trabalhar com a inclusão de alunos com deficiência (geralmente é destinada apenas uma disciplina sobre o tema). Para a autora, a formação de professores deve compreender que o ambiente escolar constitui-se de indivíduos heterogêneos que necessitam de ações pedagógicas adequadas, sobretudo na educação especial. É imprescindível saber determinar as especificidades dos alunos com necessidades especiais, a fim de identificar e compreender as características das deficiências. Tornando necessária a capacitação através de atividades contextualizadas e ações práticas que favoreçam o desenvolvimento de habilidades e competências ao futuro educador.

Para SILVA (2009) os projetos políticos pedagógicos de diversas licenciaturas revelam o problema da formação de futuros docentes: a inserção da temática da educação especial e inclusiva ainda deve ser construída Dentre os cursos analisados pelo autor, $45 \%$ apresentam em seus currículos o debate a respeito desta temática, porém $55 \%$ sequer abordam o tema.

Analisando documentos legais sobre educação especial na universidade pública e sobre a formação de docentes para atuar na educação especial, BRAGA (2009) apresenta resultados que
Realização:

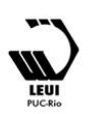




\section{$16^{\circ}$ \\ ERGODESIGN USIHC CINAHPA}

evidenciam, de certa forma, que houve avanço, porém lento, inspirando novas reflexões a fim de proporcionar a reformulação de matrizes curriculares.

A formação de docentes deve estar embasada, sobretudo, de maneira prática, para que se compreendam as maneiras como os alunos desenvolvem suas atividades. O futuro docente deve compreender que não há um padrão igualitário de aprendizagem e que todos os alunos possuem dificuldades e potencialidades diferentes.

Segundo FUSARI e RIOS (1995), a educação continuada deve ocupar-se de estratégias para capacitar os educadores, favorecendo a adequação pedagógica, tendo em vista que se vive numa sociedade onde novos paradigmas educacionais emergem constantemente.

De acordo com HUMMEL (2015), do ponto de vista da formação do docente, para atuar em contextos escolares com alunos portadores de deficiência, transtornos globais de desenvolvimento, altas habilidades ou superdotação, as contribuições da pesquisa não se encerram.

\section{Considerações Finais}

Para MANTOAN (2003), ao se pretender que a escola seja inclusiva, é urgente que seus planos se redefinam para uma educação voltada para a cidadania global, plena, livre de preconceitos, reconhecendo e valorizando as diferenças. Corroborando esse conceito, MORAES (2003) destaca que a educação é um processo que só acontece por meio das relações de cuidado na convivência das diversidades. Educar é viver junto às potencialidades, respeitando as diferenças na aceitação do outro.

As T.A.'s não devem ser vistas somente como algo conhecido e pressuposto, porque seu uso e seu impacto são fortemente influenciados pelas representações e pelas crenças referentes a ela por parte de usuários e não usuários. Entretanto, a introdução forçada das T.A.'s na educação não $16^{\circ}$ Ergodesign - Congresso Internacional de Ergonomia e Usabilidade de Interfaces Humano Tecnológica: Produto, Informações Ambientes Construídos e Transporte

$16^{\circ}$ USIHC - Congresso Internacional de Ergonomia e Usabilidade de Interfaces Humano Computador

CINAHPA | 2017 - Congresso Internacional de Ambientes Hipermídia para Aprendizagem.

transforma as pedagogias existentes, sendo necessário um enfoque nas discussões entre os professores para o trabalho interativo e cooperativo sobre como esses apoios tecnológicos podem ser usados para ampliar e transformar a prática docente.

A concepção de inclusão tornou-se mais complexa e democrática com as T.A.'s para uma inclusão de todos, pois houve avanços gradativos na produção do conhecimento humano, que abriram e expandiram o processo de inclusão de indivíduos com deficiência na sociedade.

\section{BIBLIOGRAFIA}

BERSCH, Rita; PELOSI, Miryam. Portal de ajudas técnicas para a educação: equipamento e material pedagógico para a educação, capacitação e recreação da pessoa com deficiência física. Tecnologia assistiva: recursos de acessibilidade ao computador. Brasília: MEC/SEESP, 2006.

BRAGA, D. R. Formação inicial de professores e educação especial. $32^{\mathrm{a}}$ REUNIÃO ANUAL DA ANPED - Sociedade, cultura e educação: novas regulações? Caxambu, 4-7 de outubro de 2009. Caxambu: ANPED, 2009. Disponível em: <http://www.anped.org.br/reunioes/32ra/arquivos/t rabalhos/GT08-5205--Int.pdf >. Acesso em: 18/11/2016.

BRASIL. Conselho Nacional de Educação.

Resolução CNE/CP 1, de 18 de fevereiro de 2002. Institui diretrizes curriculares para a formação de professores da educação básica. Brasília, 2002. Disponível em:

<http://portal.mec.gov.br/seesp/arquivos/pdf/res1_ 2.pdf>. Acesso em 15/11/2016.

BRASIL. Conselho Nacional de Educação. Câmara de Educação Básica. Resolução n. 4 de 2 de outubro de 2009. Diretrizes operacionais para o atendimento educacional especializado na educação básica, modalidade educação especial. Brasília: Diário Oficial da União, n. 190, Seção 1, p. 17,05 out. 2009.
Realização:

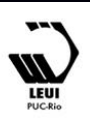




\section{$16^{\circ}$ \\ ERGODESIGN USIHC CINAHPA}

BRASIL. Decreto $n^{0}$ 5.296. Regulamentação das Leis 10.048 de 08 de Novembro de 2000 e 10.098 de 19 de Dezembro de 2000. Estabelece normas gerais e critérios básicos para a promoção da acessibilidade das pessoas portadoras de deficiência ou com mobilidade reduzida. Brasília, 2004. Disponível em:

<http://www.planalto.gov.br/ccivil_03/_ato20042006/2004/decreto/d5296.htm> Acesso em: $17 / 11 / 2016$

BRASIL. Lei no 9.394. LDB: Lei de Diretrizes e Bases da Educação Nacional, de 20 de dezembro de 1996. Estabelece as Diretrizes e Bases da educação Nacional. Brasília, 1996. Disponível em: <www.planalto.gov.br/ccivil_03/leis/19394.htm> Acesso em: 17/11/2016.

CAMBIAGHI, S.; YOUSSEF, A., 2007, Desenho Universal: Métodos e técnicas para arquitetos e urbanista, SENAC, São Paulo, p. 269.

CONTE, Elaine; BASEGIO, Antônio C. Tecnologias Assistivas: Recursos Pedagógicos Para a Inclusão Humana, Revista Temas em Educação, João Pessoa, v.24, n. 2, p. 28-44, jul.dez. 2015.

COOK, Albert M; POLGAR, Jan Miller. Cook e Hussey - Assistive Technologies: Principles and Practices. Editora Mosby, 1995

FUSARI, J. C.; RIOS, T. A. Formação continuada dos profissionais do ensino.

Cadernos CEDES, Campinas, n.36, p. 37-45, 1995.

HUMMEL, Eromi Izabel. Tecnologia Assistiva: A Inclusão na Prática. $1^{a}$ Edição, Curitiba: Appris, 2015.

KLEINA, Claudio. Tecnologia Assistiva em Educação Especial e Educação Inclusiva. ${ }^{a}$ Edição, Curitiba: Intersaberes, 2012.

MANTOAN, Maria Teresa Eglér. A integração de pessoas com deficiência: contribuição para uma reflexão sobre o tema. São Paulo:

Memnon/SENAC, 1997. $16^{\circ}$ Ergodesign - Congresso Internacional de Ergonomia e Usabilidade de Interfaces Humano Tecnológica: Produto, Informações Ambientes Construídos e Transporte

$16^{\circ}$ USIHC - Congresso Internacional de Ergonomia e Usabilidade de Interfaces Humano Computador

CINAHPA | 2017 - Congresso Internacional de Ambientes Hipermídia para Aprendizagem.

\begin{abstract}
Ajudas Técnicas Para Educação. Equipamento e Material Pedagógico especial para Educação, Capacitação e Recreação da Pessoa com

Deficiência Física: recursos adaptados. $2^{\mathrm{a}}$ Edição. Brasília: MEC 2002, v.1.
\end{abstract}

MERCADO, Luís Paulo Leopoldo (Org.). Novas tecnologias na educação: reflexões sobre a prática. Maceió: Edufal, 2002.

MORAES, M. Cândida. Educar na biologia do amor e da solidariedade. Petrópolis, RJ: Vozes, 2003.

NICKEL, Elton M. Sistematização da implementação de tecnologia assistiva para o contexto educacional. Florianópolis: UFSC, 2012

OLIVEIRA, E. da S. G.; GLAT, R. Educação

Inclusiva: Ensino Fundamental para os Portadores de Necessidades Especiais. In: VALLE, B. de B. R. et AL. Fundamentos teóricos e metodológicos do ensino fundamental. Curitiba: Iesde, 2003.

SILVA, L. C. Políticas públicas de formação de professores: vozes e vieses da educação inclusiva. 2009. Tese (Doutorado em Educação) -

Universidade Federal de Uberlândia, Uberlândia, 2009.

VALENTE, J. A. Liberando a mente: computadores na educação especial. Campinas: Ed. da UNICAMP, 1991.

\section{Agradecimentos}

Gostaria de agradecer à Fundação Catarinense de Educação Especial e, especialmente, seus servidores por serem sempre tão receptivos e prestativos aos visitantes, tornando as visitas à instituição sempre muito agradáveis. Assim como também gostaria de estender os agradecimentos ao meu orientador, Elton Moura Nickel, aos demais professores e aos colegas de turma do Programa de Pós-Graduação em Design da Universidade do Estado de Santa Catarina.

MANZINI E. J.; SANTOS, M. C. F. Portal de

Realização:

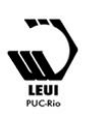

